\title{
PENATALAKSANAAN PSIKOGERIATRI DI UPT PELAYANAN SOSIAL TRESNA WERDHA HUSNUL KHOTIMAH PEKANBARU
}

\author{
${ }^{1)}$ Tesha Hestyana Sari, ${ }^{2)}$ Rusherina, ${ }^{3)}$ Kurniawati \\ ${ }^{1,2,3)}$ Poltekkes Kemenkes Riau \\ 1,2,3)Jl. Melur 103 Pekanbaru - Riau - Indonesia \\ E-mail : tesahesty@gmail.com
}

\begin{abstract}
ABSTRAK
Peningkatan jumlah lansia juga mengakibatkan berbagai permasalahan dalam kehidupan saat ini. Beberapa masalah tersebut diantaranya adalah tingkat kemandirian lansia yang menurun karena adanya kemundurun fungsi tubuh, psikis dan juga dari fungsi sosial. Tidak seluruhnya lansia tinggal bersama keluarga ataupun anak-anaknya. Beberapa lansia harus tinggal di Panti Werdha seperti di UPT. Pelayanan Sosial Tresna Werdha Khusnul Khotimah Pekanbaru. Lansia yang berada di panti werdha tidak seluruhnya sehat. Sebagian lansia memiliki penyakit seperti hipertensi. Gastritis, post stroke, halusinasi, isolasi sosial, skizofrenia dan lain-lain. Panti werdha Khusnul Khotimah Pekanbaru telah membuat jadwal kegiatan agar lansia tetap dapat beraktivitas di lingkungan Panti Werdha. Panti memiliki jadwal dalam seminggu seperti ceramah agama, membuat keterampilan, bimbingan sosial, pemeriksaan kesehatan, wirid dan senam. Namun demikian, tidak seluruhnya lansia ikut dalam kegiatan tersebut. Berdasarkan data tersebut, terlihat bahwa lansia yang berada di panti memiliki masalah kesehatan, baik secara fisik serta psikologis. Tujuan umum dari kegiatan pengabdian kepada masyarakat ini adalah untuk melaksanakan pengabdian masyarakat berupa penatalaksanaan psikogeriatri berupa Brain Gym, Art Therapy dan Reminiscence Therapy. Metode pelaksanaan berupa praktik secara lansung. Capaian dari kegiatan ini adalah dilaksanakannya kegiatan pengabdian masyarakat, adanya peningkatan kognitif pada lansia serta tidak adanya lansia yang memiliki tanda dan gejala depresi. Rekomendasi dari hasil kegiatan ini adalah hendaknya ada pasrtisipasi dari pihak pengurus Panti agar kegiatan ini dapat dilaksanakan oleh terapis yang sudah terlatih agar kegiatan ini dapat berkelanjutan.
\end{abstract}

Kata Kunci: Brain Gym, Art Therapy, Reminiscence Therapy, Lansia, Psikogeriatri

\begin{abstract}
The increase in the number of elderly also causes various problems in today's life. Some of these problems include the decreased level of independence of the elderly due to a decline in body, psychological and social functions. Not all of the elderly live with their families or children. Some of the elderly have to live in a nursing home like at UPT. Tresna Werdha Husnul Khotimah Social Services Pekanbaru. The elderly who are in nursing homes are not all healthy. Some of the elderly have diseases such as hypertension. Gastritis, post stroke, hallucinations, social isolation, schizophrenia and others. Panti Werdha Khusnul Khotimah Pekanbaru has made a schedule of activities so that the elderly can still be active in the Panti Werdha environment. The orphanage has a weekly schedule such as religious lectures, making skills, social guidance, health checks, wirid and gymnastics. However, not all of the elderly participated in these activities. Based on these data, it can be seen that the elderly who are in nursing homes have health problems, both physically and psychologically. The general purpose of this community service activity is to carry out community service in the form of psychogeriatric management in the form of Brain Gym, Art Therapy and Reminiscence Therapy. The implementation method is in the form of direct practice. The achievements of this activity are the implementation of community service activities, cognitive improvement in the elderly and the absence of elderly people who have signs and symptoms of depression. The recommendation from the results of this activity is that there should be participation from the Panti management so that this activity can be carried out by trained therapists so that this activity can be sustainable.
\end{abstract}

Keyword: Brain Gym, Art Therapy, Reminiscence Therapy, Elderly, Psychogeriatrics

\section{PENDAHULUAN}

\section{Analisis Situasi}

Mitra Pengabdian masyarakat ini adalah UPT. Pelayanan Sosial Tresna Werdha Khusnul Khotimah Pekanbaru. PSTW Khusnul Khotimah mempunyai tugas melaksanakan sebagian kegiatan teknis operasional dan atau kegiatan teknis penunjang Dinas Sosial di bidang Pelayanan sosial panti jompo. Dalam kegiatannya, PSTW Khusnul Khotimah melaksanakan beberapa 
layanan yaitu pelaksanaan bimbingan agama, kegiatan keterampilan, pemeriksaan kesehatan, bimbingan psikolog, kegiatan senam lansia dan kegiatan rekreasi. Saat ini kapasitas daya tampung di PSTW Khusnul Khotimah adalah 80 orang Lansia.

Organisasi kesehatan dunia WHO membagi batasan lansia menjadi beberapa kategori yaitu usia pertengahan (45-59), lanjut usia (60-74 tahun), lanjut usia tua (75-90 tahun) dan usia sangat tua (lebih dari 90 tahun) [1]. Dari beberapa definisi tersebut dapat disimpulkan bahwa lansia merupakan seseorang yang telah mencapai usia 60 tahun ke atas.

Berdasarkan data Badan Pusat Statistik [2], jumlah lansia yang ada di Indonesia diperkirakan mencapai $13,2 \%$ dan menjadi 25,5\% pada tahun 2050. Disamping itu data lainnya menunjukkan bahwa Indonesia memasuki periode aging population dimana terjadi peningkatan umur harapan hidup dengan bertambahnya jumlah lansia. Data tersebut terlihat pada tahun 2010 terdata lansia sebanyak 18 juta jiwa (7,56\%). Selanjutnya pada tahun 2019 jumlah lansia meningkat menjadi 25,9 juta jiwa $(9,7 \%)$ dan akan terus meningkat diperkirakan pada tahun 2035 menjadi 48,2 juta jiwa $(15,77 \%)$ [3].

Meningkatnya jumlah lansia tentunya memiliki tantangan untuk negara terutama dalam hal pemeliharaan kesehatan lansia. Lansia yang mengalami proses penuaan akan mengalami perubahan kondisi seperti fisik, mental, psikososial dan juga perubahan lain seperti pekerjaan serta kehidupan sosial lansia. Lansia dengan proses penuaannya diikuti dengan keterbatasan kemandirian, permasalahan mobilitas, kelemahan, munculnya masalah fisik dan mental serta penurunan status sosial ekonomi [4].

Permasalahan tersebut dapat menimbulkan masalah kesehatan jiwa seperti stres, kesepian, depresi, skizofrenia, insomnia dan masalah mental lainnya. Selain itu, permasalahan tersebut juga dapat menimbulkan kesehatan fisik seperti gastritis, hipertensi, diabetes dan lain-lain. Lansia yang tinggal di pelayanan sosial Khusnul Khotimah mempunyai masalah kesehatan baik fisik maupun masalah psikologis. Berdasarkan data Riskesdas tahun 2007 dan 2013, lansia yang mengalami masalah gangguan jiwa yaitu $12 \%$ pada lansia yang tinggal dikomunitas, $30 \%$ terdapat pada lansia di fasilitas pelayanan primer maupun rawat inap, serta $70 \%$ terdapat pada lansia yang tinggal di unit pelayanan sosial lanjut usia seperti panti werdha.

Berdasarkan hasil wawancara dan observasi dengan pihak pelayanan sosial Khusnul Khotimah, beberapa orang lansia kurang mau mengikuti kegiatan yang diadakan pihak PSTW yang telah terjadwal. Perawat mengatakan biasanya lansia yang ikut kegiatan senam setiap hari sabtu sekitar 15 sampai dengan 20 orang. Sementara itu kegiatan membuat keterampilan hanya sekitar 6 orang. Perawat PSTW Khusnul Khotimah juga mengatakan ada melakukan senam dengan pihak instruktur yang telah ditunjuk namun sejak masa pandemik tidak pernah dilakukan lagi serta belum ada kegiatan Reminiscence Therapy di jadwal kegiatan lansia di PSTW Khusnul Khotimah Pekanbaru. Tujuan umum dari kegiatan pengabdian kepada masyarakat ini adalah untuk melaksanakan pengabdian masyarakat berupa penatalaksanaan psikogeriatri. Sementara itu tujuan khususnya adalah melakukan Brain Gym, Art Therapy, dan melakukan Reminiscence Therapy pada lansia.

Brain gym merupakan senam otak dengan cara latihan yang berupa gerakan -gerakan ringan melalui olah tangan dan kaki yang dapat memberikan stimulus atau rangsangan pada otak sehingga dapat menyeimbangkan aktivitas kedua hemisfer otak secara bersamaan serta meningkatkan kemampuan kognitif. Brain gym pada dasarnya berupaya mengaktifkan otak kiri 
dan otak kanan secara optimal [5]. Senam otak/ brain gym yang dilakukan secara teratur mampu menurunkan hormon stres seperti kortisol, epinefrin dan dopac (katabolit utama dopamin). Adapun besaran penurunnya yaitu kortisol 39\%,epinefrin 70\% dan dopac 38\% [6].

Selain mampu menurunkan kadar hormon stres, brain gym juga dapat menigkatkan hormon endorfin, serotonin, serta hormon melatonin. Hormon-hormon tersebut mampu memberikan perasaan nyaman, tenang, dan rileks. Hormon endorfin berfungsi menekan sinyal nyeri yang masuk ke dalam sistem saraf dengan mengaktifkan sistem pengaturan nyeri sehingga menimbulkan efek relaksasi. Kemudian hormon serotonin mampu memberikan dorongan pada sistem limbik untuk meningkatkan perasaan bahagia, rasa puas,nafsu makan yang baik,perasaan yangnyaman serta meningkatkan keseimbangan psikomotor. Selanjutnya hormon melatonin mampu membuat otot tidak tegang dan memberikan rasa nyaman [6].

Selanjutnya Art therapy merupakan sebagai kegiatan yang dilakukan pada klien dengan masalah mental dengan menggunakan media yang artristik, dengan proses yang kreatif dan menghasilkan suatu kerajinan seni untuk mengeksplorasi perasaan, meningkatkan kesadaran diri, mengelola perilaku dan meningkatkan ketrampilan sosial, meningkatkan orientasi dan menurunkan kecemasan [7]. Art therapy merupakan gabungan dari pendekatan mind body dimana klien dapat mengekspresikan perasaannya melalui sensori ataupun kinestetik [8]. Berdasarkan penelitian oleh Kim [9], Art therapy dapat mengurangi emosi negatif, meningkatkan konsep diri serta menurunkan tingkat kecemasan. Penelitian lainnya oleh Putri [10] menunjukan pada kelompok intervensi lansia dengan demensia yang diberikan latihan senam otak sebanyak tiga kali seminggu dan art theraphy sebanyak dua kali seminggu, terdapat peningkatan fungsi kognitif yang bermakna.

Kegiatan ketiga yang akan dilakukan yaitu terapi Reminiscence. Terapi Reminiscence merupakan salah satu intervensi yang menggunakan memori untuk memelihara kesehatan mental dan meningkatkan kualitas hidup [11]. Terapi Reminiscence memiliki fungsi escapist dimana mengingat keindahan masa lalu untuk melupakan sejenak hal-hal yang tidak menyenangkan di masa sekarang dan mengurangi perasaan-perasaan negatif pada lansia [12]. Reminiscence merupakan teknik yang digunakan untuk mengingat serta membicarakan kehidupan seseorang [13].

Berdasarkan penelitian Hsieh et al [14] menyatakan bahwa reminiscence group therapy mampu menurunkan gejala depresi dan apatis di nursing home resident dengan level demensia yang ringan sampai sedang. Terapi ini dapat diberikan pada lansia secara individu, keluarga dan juga kelompok [13].

\section{METODE PELAKSANAAN}

Tahap pertama adalah berupa perencanaan kegiatan yang akan dilakukan. Proses perencanaan terdiri dari identifikasi kebutuhan, identifikasi potensi dan kelemahan yang ada, menentukan jalan keluar dan kegiatan yang akan dilakukan, dan membuat pengorganisasian kegiatan. Tim pengabmas melakukan survey awal pada tanggal 12 Desember 2019. Tim pengabmas melakukan diskusi dengan Kasi Pelayanan Sosial beserta perawat di klinik PSTW Khusnul Khotimah Pekanbaru untuk survei awal dalam rangka perencanaan kegiatan pengabdian masyarakat di PSTW Khusnul Khotimah Pekanbaru.

Tahap kedua adalah pelaksanaan kegiatan pengabdian berupa solusi yang telah disetujui 
kepala UPT. Pelayanan Sosial Tresna Werdha Pekanbaru. Pelaksanaan kegiatan dilakukan selama 4 kali terdiri dari pengkajian awal pada lansia, kegiatan brain gym, kegiatan art therapy dan kegiatan Reminiscence therapy serta diakhiri dengan evaluasi kegiatan pengabdian masyarakat.

Dalam kegiatan ini akan diadakan evaluasi untuk mengetahui adanya perubahan tingkat depresi pada lansia di PSTW Khusnul Khotimah Pekanbaru. Evaluasi tersebut dilakukan sebelum kegiatan diberikan dan setelah kegiatan selesai. Dari data tersebut dapat diketahui apakah kegiatan pengabmas berjalan efektif dan mengenai sasaran. Teknik pengumpulan data dalam kegiatan ini menggunakan screening GDS (Geriatric Depression Scale) untuk melihat ada atau tidaknya masalah depresi dan instrumen MMSE (Mini Mental State Examination) untuk melihat tingkat kognitif lansia. Pengambilan data telah dilakukan kepada 30 orang lansia di PSTW Khusnul Khotimah Pekanbaru.

\section{HASIL}

\section{Dokumentasi Kegiatan}
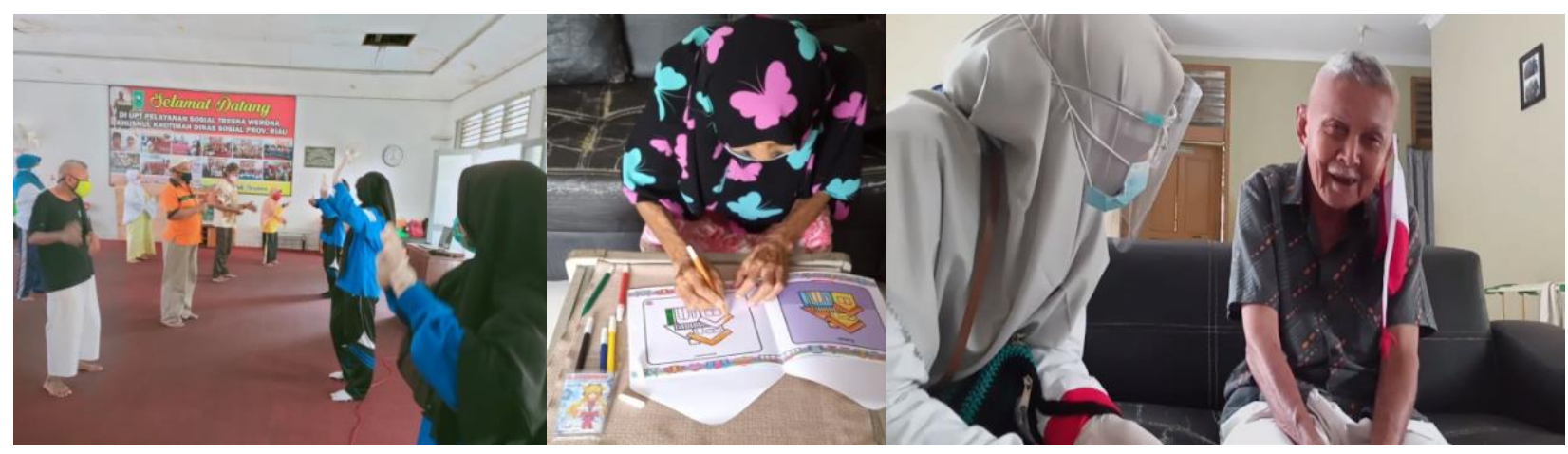

Gambar 1. Kegiatan Brain Gym, Art Therapy, dan Reminiscence Therapy

Gambar di atas adalah beberapa kegiatan yang dilaksakan oleh tim pengabmas. Diawali dengan pengkajian dan screening terlebih dahulu kemudian menetapkan jumlah lansia yang dapat mengikuti kegiatan. Selanjutnya seluruh rangkaian kegiatan pengabmas dilakukan dengan protokol kesehatan.

Tabel 1. Tabel Pengolahan Data

\begin{tabular}{clccc}
\hline No & $\begin{array}{c}\text { Nama } \\
\text { Lansia }\end{array}$ & Skor GDS & $\begin{array}{c}\text { Skor MMSE } \\
\text { (sebelum kegiatan) }\end{array}$ & $\begin{array}{c}\text { Skor MMSE } \\
\text { (setelah kegiatan) }\end{array}$ \\
\hline 1 & Tn. B & 2 & 24 & 27 \\
\hline 2 & Tn. D & 3 & 22 & 24 \\
\hline 3 & Tn.E & 2 & 30 & 30 \\
\hline 4 & Ny.S & 1 & 23 & 23 \\
\hline 5 & Tn.Y & 0 & 30 & 30 \\
\hline 6 & Tn.Kh & 2 & 30 & 30 \\
\hline 7 & Tn.L & 2 & 30 & 24 \\
\hline 8 & Tn. Mi & 2 & 24 & 28 \\
\hline 9 & Tn.Mu & 0 & 27 & 28 \\
\hline 10 & Tn.Yu & 0 & 27 & 26 \\
\hline 11 & Tn.N & 2 & 26 & 30 \\
\hline 12 & Ny.N & 2 & 30 & \\
\hline
\end{tabular}




\begin{tabular}{cllcc}
\hline 13 & Ny.Nu & 3 & 30 & 30 \\
\hline 14 & Ny. Nrm & 1 & 24 & 24 \\
\hline 15 & Ny.Nrh & 0 & 24 & 24 \\
\hline 16 & Tn.Rh & 2 & 27 & 27 \\
\hline 17 & Ny.Sj & 2 & 22 & 22 \\
\hline 18 & Tn.Sw & 2 & 30 & 29 \\
\hline 19 & Ny.Srt & 3 & 27 & 27 \\
\hline 20 & Ny.Sar & 4 & 30 & 30 \\
\hline 21 & Ny.Suk & 0 & 28 & 28 \\
\hline 22 & Tn.Tuk & 0 & 24 & 24 \\
\hline 23 & Tn.Yn & 0 & 24 & 24 \\
\hline 24 & Tn.Da & 1 & 27 & 26 \\
\hline 25 & Tn.De & 1 & 27 & 24 \\
\hline 26 & Tn.Ce & 2 & 28 & 28 \\
\hline 27 & Tn.U & 2 & 30 & 30 \\
\hline 28 & Ny. Sy & 3 & 22 & 30 \\
\hline 29 & Ny.Si & 1 & 30 & 30 \\
\hline 30 & Tn.Su & 1 & 27 & 27,2 \\
\hline Nilai Mean (pengukuran MMSE) & 26,8 & 2,65 \\
\hline \multicolumn{5}{c}{ STD (pengukuran MMSE) } \\
\hline \multicolumn{7}{c}{}
\end{tabular}

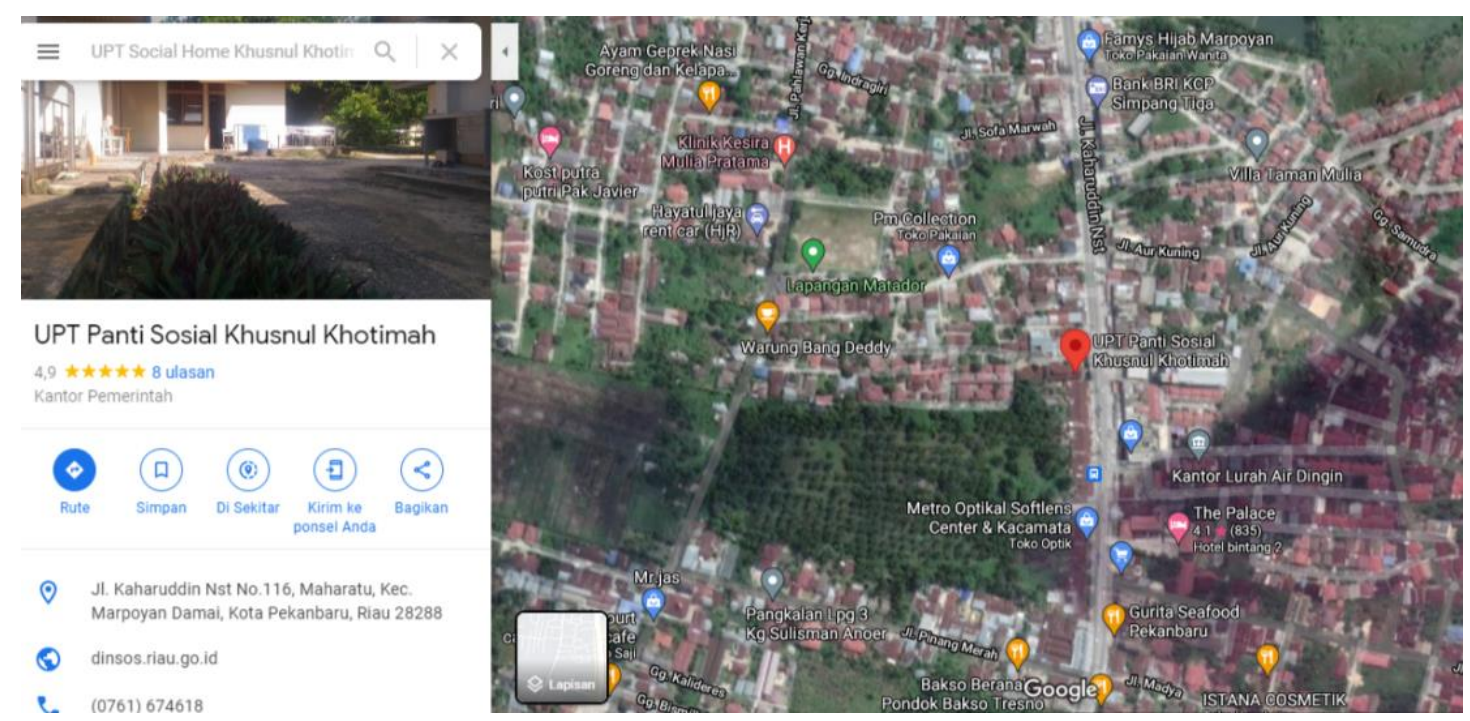

Lokasi pengabdian masyarakat adalah di UPT. Pelayanan Sosial Tresna Werdha Khusnul Khotimah Jl. Kaharuddin Nst No.116, Maharatu, Kec. Marpoyan Damai, Kota Pekanbaru, Riau28288.

\section{KESIMPULAN}

Berdasarkan hasil kegiatan pengabdian masyarakat, dapat disimpulkan bahwa kegiatan senam brain gym, art therapy dan reminiscence therapy dapat dilaksanakan kepada lansia yang berada di PSTW Husnul Khotimah. 


\section{DAFTAR PUSTAKA}

[1] Notoadmodjo S, "Kesehatan Masyarakat Ilmu dan Seni", Jakarta: Rineka Cipta, 2011.

[2] Badan Pusat Statistik. (2015). Statistik Penduduk Lanjut Usia 2015 [online]. Avalaible: http://www.bps.go.id.

[3] Depkes RI. (2019). Indonesia Memasuki Periode Aging Population. Diakses pada tanggal 10 Desember 2019 [online]. Avalaible: https://www.depkes.go.id/article/view/19070500004/indonesia-masuki-periode-agingpopulation.html

[4] World Health Organization. (2013). Mental Health And Older Adults [online]. Avalaible: http://www.who.int/mediacentre/factsheets/fs381/en/

[5] Razak, "Meningkatkan Kemampuan Membaca Permulaan Bagi Anak Kesulitan Belajar Melalui Brain Gym", 2014.

[6] Sari, et al," Pengaruh Senam Otak terhadap Tingkat Stres Lansia di Panti Sosial Tresna Werdha Jara Mara Pati Singaraja", J.Keperawatan Sriwijaya, vol.2, no.1 ISSN no 2355 5459, 2015.

[7] American Art Therapy Association. (2014). Definition statement [online]. Avalaible: http://www.arttherapy.org

[8] Im et al," Effects of art and music therapy on depression and cognitive function of the elderly", Technology and Health Care, 22(3), 453-458, 2014.

[9] Kim, S. K,"A randomized, controlled study of the effects of art therapy on older KoreanAmericans' healthy aging", The Arts in Psychotherapy, vol.40, no,1,pp.158-164, 2013.

[10] Putri et al,"Pengaruh Latihan Senam Otak dan Art Therapy terhadap Fungsi Kognitif Lansia dengan Demensia di PSTW Yogyakarta Unit Budi Luhur dan Abiyoso", Fakultas Ilmu Keperawatan Universitas Indonesia, Depok, 2012.

[11] Chen et al," The effects of reminiscence therapy on depressive symptoms of Chine se elderly: Study protocol of a randomized controlled trial", BMC Psychiatry, 2012.

[12] Utami, M.S.S,"Terapi Reminiscence dan Snoezelen untuk Kesehatan Lanjut Usia, Semarang: Universitas Katolik, 2012.

[13] Sumartono, Grispenjas M.P et al. (2014). Reminiscence Therapy dengan Metode Terapi Aktivitas Kelompok meningkatkan Fungsi Kognitif pada Lansia [online]. Available: https://e-journal.unair.ac.id/IJCHN/article/view/12218/7092

[14] Hsieh et al," Reminiscence Group Therapy on Depression and Apathy in Nurshing Home Residents With Mild-to-moderate Dementia", J. of Experimental \& Clinical Medicine, vol.2, no.2,pp.72-78, 2010. 